\title{
ROLLEDTEXTURES AND MAGNETIC PROPERTIES OF REGULAR GRAIN ORIENTED 3\% SILICON STEEL WITH VERY LOW THICKNESS
}

\author{
C. H. HAN and J. C. SHIN \\ Research Institute of Industrial Science and Technology \\ Specialty Steel Research, P.O.Box 135, Pohang, Korea
}

\section{ABSTRACT}

Regular grain oriented $3 \mathrm{wt. \%}$ silicon steel sheets of $0.30 \mathrm{~mm}$ thick, having orientations near (110)[001], were cold rolled to $0.050 \mathrm{~mm}$ thick and their 0.100 and $0.050 \mathrm{~mm}$ thick foils were annealed in order to study the changes in rolled textures, recrystallized textures and magnetic properties with decreasing the sheet thickness. The results are summarized as follows:

(110)[001] grains of recrystallized sheets are changed to (111)[112] with cold rolling and (111)[112] grains of cold rolled sheets are restored to (110)[001] with annealing. The stronger (111)[112] textures are formed in the cold rolled sheets, the stronger (110)[001] textures are developed in the recrystallized sheets, when the cold rolled sheets of 0.100 and $0.050 \mathrm{~m}$ thick were annealed to and above $600{ }^{\circ} \mathrm{C}$ for 1 hour, recrystallization occurred to show restoring the magnetic properties to those of the initially secondary recrystallized $0.30 \mathrm{~mm}$ thick sheets with forming similary strong (110)[001] textures.

\section{INTRODUCTION}

The magnetic property of grain oriented silicon steel sheets improves when the deviation of (110)[001] texture to the rolling direction is reduced. Several other ways to reduce the core loss have been practically applied: reducing the sheet thickess, applying extemal tensile stress to the sheet surface with insulation coating and modifying the magnetic domain with mechanical scratching or laser scribing. In particular, more importance is placed on reducing the sheet thickness because of the steel foil's applicability in higher frequency devices.

Earlier study predicted the optimum thickness, which minimizes core loss, to be 0.15 to $0.23 \mathrm{~mm}(1)$. It is recently, however, predicted to be thinner than $0.100 \mathrm{~mm}$ based on the test results of grain oriented silicon steel having mirror finished surface and other theoretical considerations which would decrease core loss(2). Since it is 
very difficult to have silicon steel rolled to below $0.100 \mathrm{~mm}$ thick having a good grain texture by conventional rolling and annealing, many studies were done with the chemically etched thin silicon steel sheets $(3,4)$. Arai et. al, however, reported the grain texture and magnetic properties of $0.100 \mathrm{~mm}$ thick high permeability grain oriented silicon steel sheets obtained by rolling and followed by annealing $(5,6)$.

In this paper, We report the influence of cold reduction and subsequent annealing on the rolled and recrystallized textures and magnetic properties of regular grain oriented silicon steel sheets rolled down to 0.100 and $0.050 \mathrm{~mm}$ thick.

\section{EXPERIMENT}

$0.30 \mathrm{~mm}$ thick grain oriented $3 \mathrm{wt} . \%$ silicon steel coils, of which magnetic induction a $800 \mathrm{~A} / \mathrm{m}$ is 1.84 Tesla, were cold rolled to $0.180,0.150,0.140,0.120$, $0.100,0.080$ and $0.050 \mathrm{~mm}$ thick after the insulation layer was removed by dipping the coils in hydrochloric acid solution. Each steel foil was cut into pieces of $30 \mathrm{X}$ $100 \mathrm{~mm}^{2}$ and annealed in a hydrogen atmosphere.

$18 \times 20 \mathrm{~mm}$ and $33 \mathrm{~mm}$ in diameter specimens were cut out of each foil and placed in an integrating specimen holder to measure the $\mathrm{X}$-ray intensities of planes by reflection method and the (200) pole figure of steel foils thicker than $0.100 \mathrm{~mm}$ by reflection method and of steel foils thinner than $0.100 \mathrm{~mm}$ by reflection and transmission $\mathrm{X}$-ray methods using $\mathrm{Mo}-\mathrm{K} \alpha$ radiation. The $\mathrm{X}$-ray integrated intensities are calculated according to the Horta's formulation(7). Magnetic induction at $800 \mathrm{~A} / \mathrm{m}$ was measured at room temperature by single strip testing.

\section{RESULTS AND DISCUSSION}

Fig. 1 shows $X$-ray integrated intensity changes with sheet thickness. In the cold rolled sheets thicker than $0.180 \mathrm{~mm}$, only the (110) diffraction is observed in contrast with the increasing (222) diffraction with decreasing the sheet thickness. In the cold rolled sheets of $0.050 \mathrm{~mm}$ thick, thus, the (222) diffraction is very strong with very weak (110) diffraction.

Since the rolled grain texture is known to have strong effects on the grain growth by annealing, the as rolled texture was firstly observed for the thin sheets of $0.180,0.150 \quad 0.100$ and $0.050 \mathrm{~mm}$ thick as shown in Fig. 2.

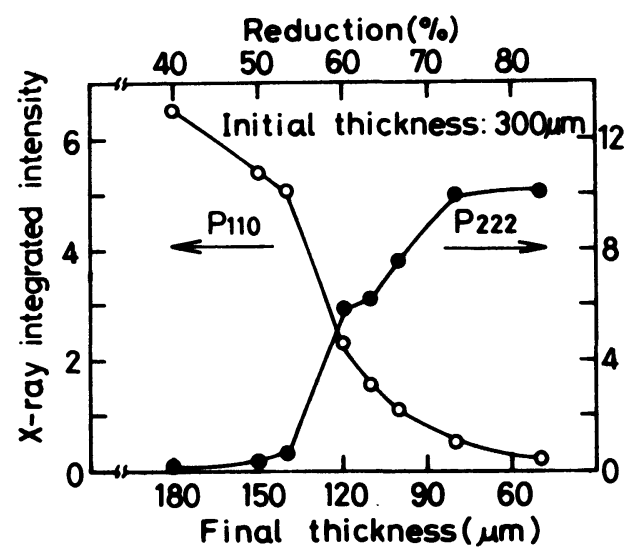

Fig. 1 The X-ray integrated intensity changes of the cold rolled sheets 

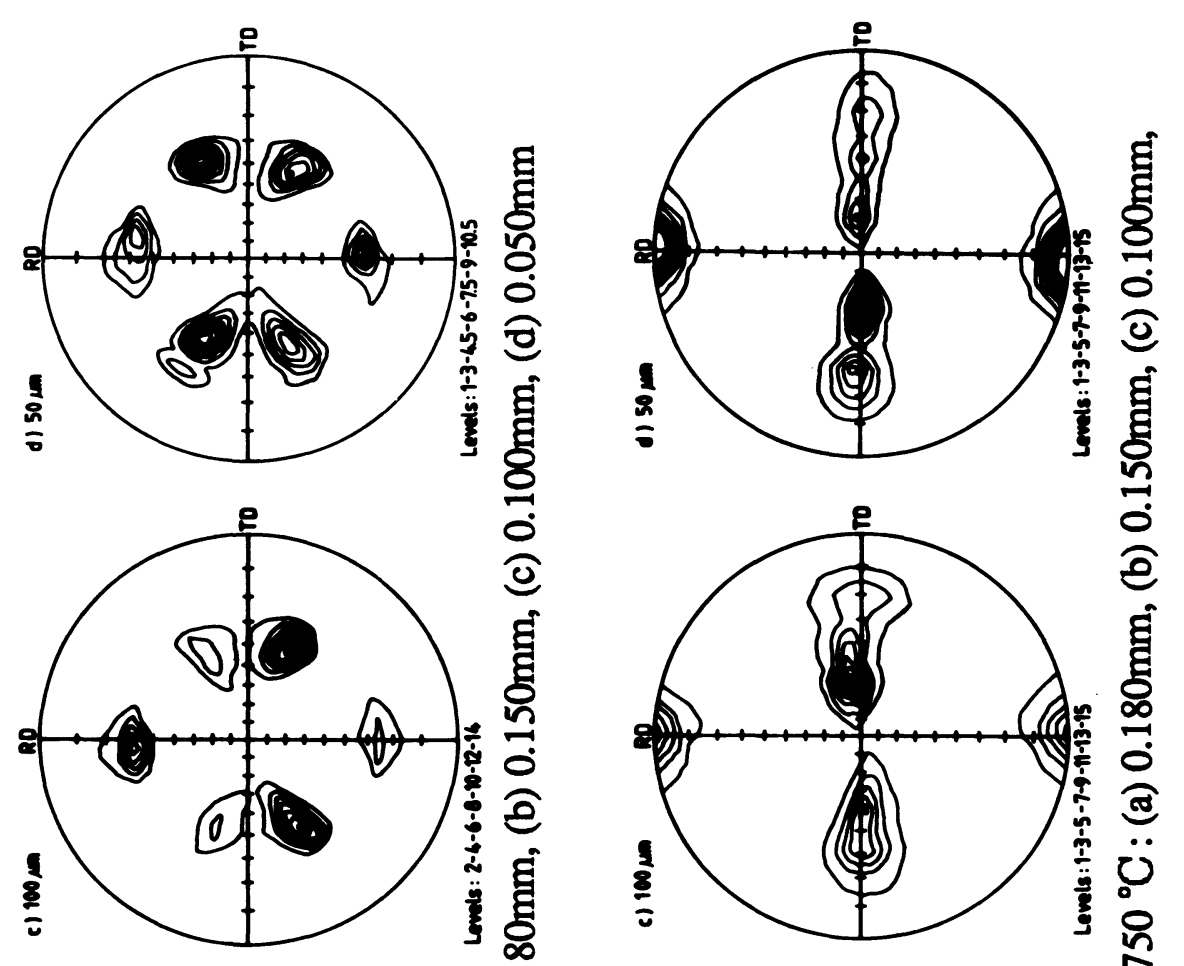

อ
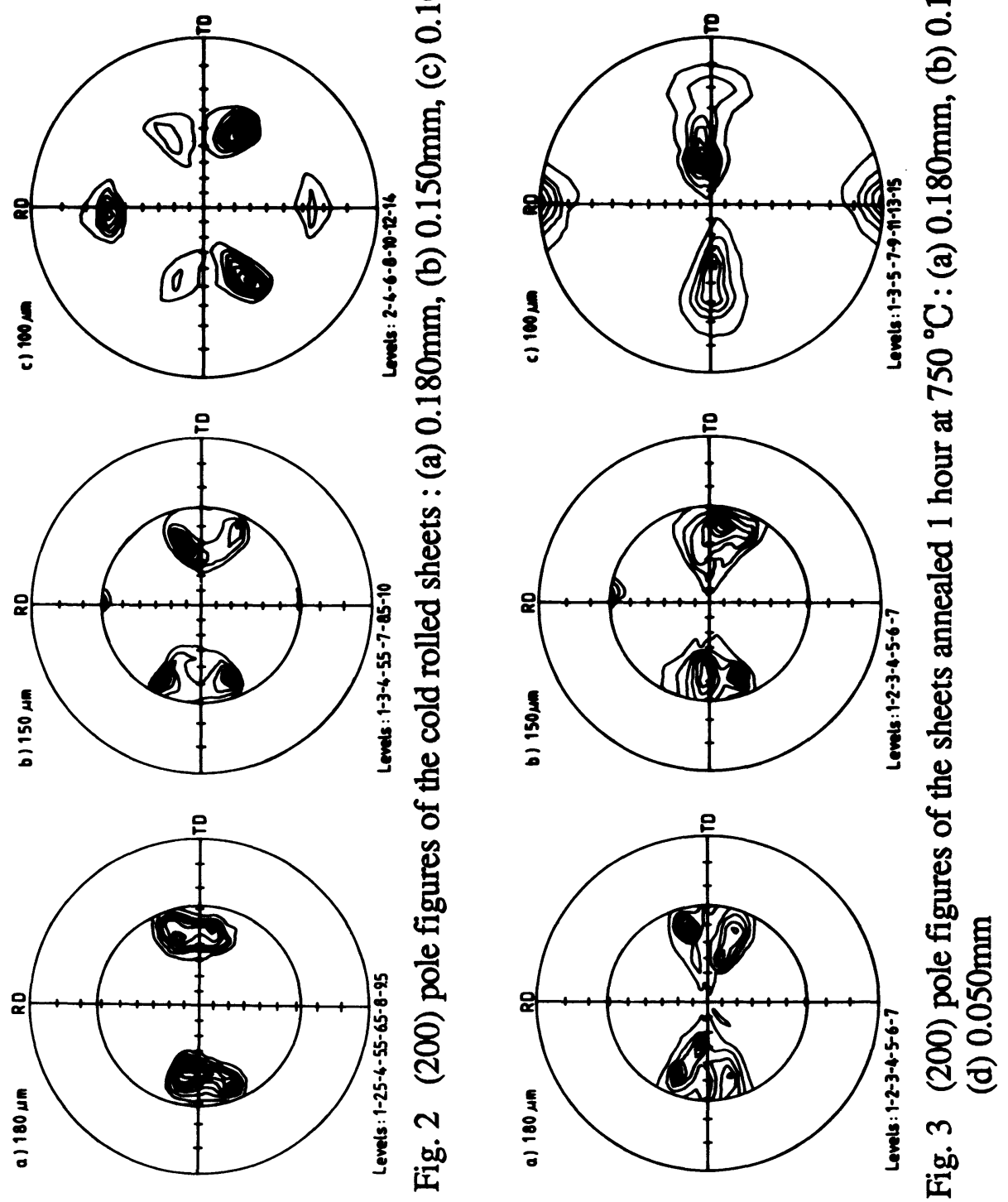
When the secondary recrystallized grain oriented silicon steel sheet, of which the texture is characterized by the (110)[001] orientation, is rolled to $0.180 \mathrm{~mm}$ thick, this major texture is still maintained in the $0.180 \mathrm{~mm}$ thick cold rolled sheet. As the thickness is thicker, its major texture is changed from the (110)[001] orientation to the (111)[112]. Thus, the (111)[112] orientation is dominant in the $0.050 \mathrm{~mm}$ thick cold rolled sheet.

The thin gauge steel sheets of $0.180,0.150,0.100$ and $0.050 \mathrm{~mm}$ thick were annealed $750^{\circ} \mathrm{C}$ for 1 hour in hydrogen atmosphere, and their (200) pole figures are determined as shown in Fig. 3. In the annealed sheets of 0.180 and $0.150 \mathrm{~mm}$ thick, the rolled textures are still observed to be diffused. The rolled texture of (111)[112] orientation is, however, replaced by the (110)[001] orientation in the $0.050 \mathrm{~mm}$ thick sheets annealed a $750^{\circ} \mathrm{C}$ for 1 hour. Therefore, it can be said that the (110)[001] grains in the regular grain oriented silicon steel sheet are changed to the (111)[112] orientation with the subsequent cold rolling and that the (111)[112] grains in the cold rolled sheet are restored to the (110)[001] orientation with recrystallization annealing. This observation is consistent with that of single crystal(8).

The dependence of the magnetic induction at $800 \mathrm{~A} / \mathrm{m}$ for the annealed sheets is shown in Fig. 4. As the sheet thickness is decreased, the magnetic induction increases and reaches to that of original regular grain oriented silicon steel sheet in the case of the $0.050 \mathrm{~mm}$ thick annealed sheet. This may tell that the (111)[112] orientation of the rolled texture is necessary to develop the (110)[001] orientation.

The X-ray intensities of the $0.100 \mathrm{~mm}$ thick sheets, annealed at the given temperatures, are shown in Fig. 5. When the annealing temperature was lower than $600^{\circ} \mathrm{C}$, the major diffraction is observed to be (222) plane together with minor diffractions of (110) and (211) planes. As the annealing temperature is increased to and above $700^{\circ} \mathrm{C}$, this major diffraction became weaker with sharply

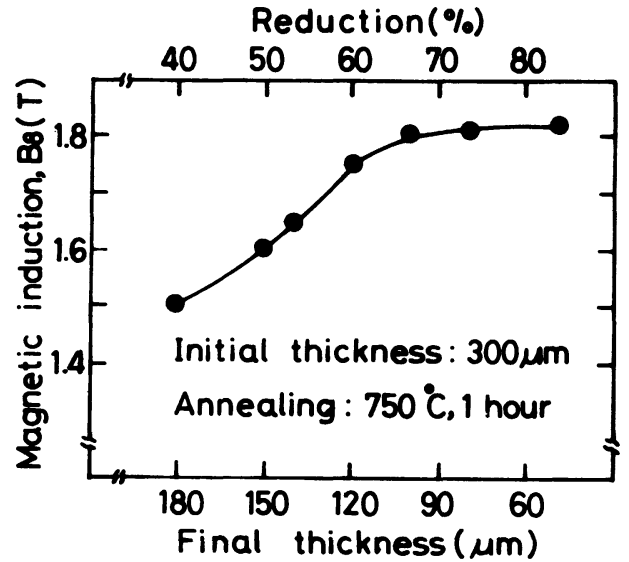

Fig. 4 The dependence of the magnetic induction a $800 \mathrm{~A} / \mathrm{m}$ of the sheets annealed 1 hour at 750 ${ }^{\circ} \mathrm{C}$ on the sheet thickness increasing (110) and (310) intensities.

Photo 1 shows the five different microstructures for the $0.100 \mathrm{~mm}$ thick cold rolled sheet: as cold rolled and annealed at $500^{\circ} \mathrm{C}, 700^{\circ} \mathrm{C}, 900^{\circ} \mathrm{C}$ and $1100^{\circ} \mathrm{C}$ for 1 hour( from top to bottom ). 


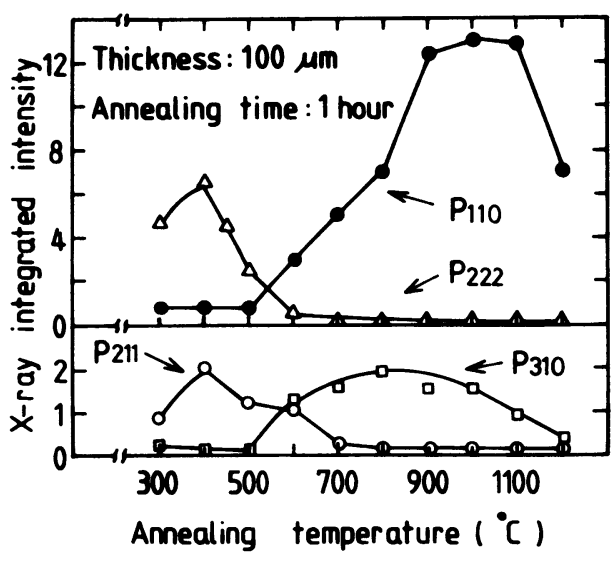

Fig. 5 P values of the $0.100 \mathrm{~mm}$ thick sheets annealed 1 hour at given temperatures

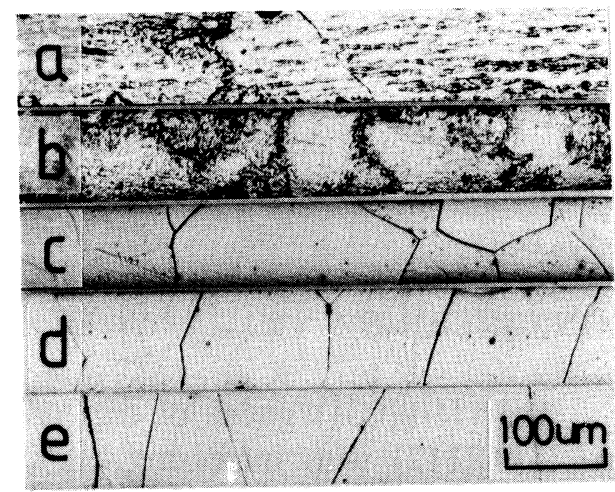

Photo 1 The microstructures of $0.100 \mathrm{~mm}$ thick sheets:(a)as rolled and annealed $1 \mathrm{hr}$. at (b) $500{ }^{\circ} \mathrm{C}$, (c) $700{ }^{\circ} \mathrm{C}$, (d) $900{ }^{\circ} \mathrm{C}$, (e) $1100^{\circ} \mathrm{C}$

In the cold rolled structure, two adjacent grains separated by a grain boundary are seen deformed. When annealed a $500^{\circ} \mathrm{C}$ for 1 hour, however, the lines of boundaries started to demarcate new grains which seem to form recrystallized grains afterwards. This is clearly seen in the other micrographs, annealed at and above 700 ${ }^{\circ} \mathrm{C}$ for 1 hour. The grains were recrystallized and grain growth proceeded by coalescence of adjacent grains.

The texture changes of the $0.050 \mathrm{~mm}$ thick sheets annealed at the given temperatures for 1 hour are similiar to those of the $0.100 \mathrm{~mm}$ thick sheets in Fig. 5, as shown in Fig. 6.

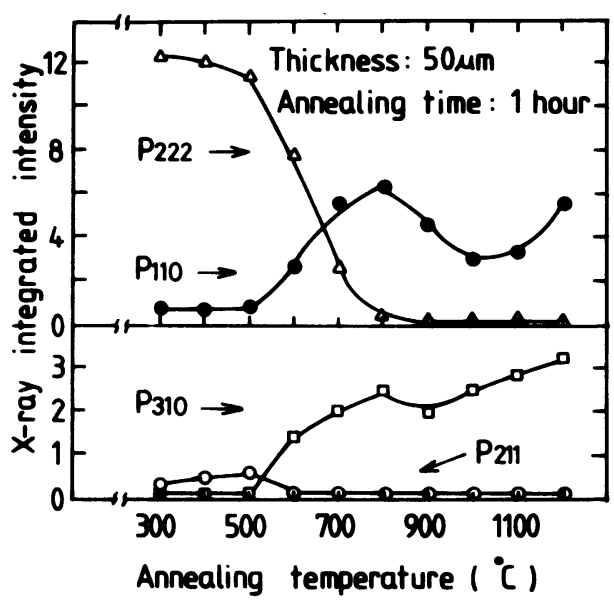

Fig. $6 \mathrm{P}$ values of the $0.050 \mathrm{~mm}$ thick sheets annealed 1 hour at given temperatures

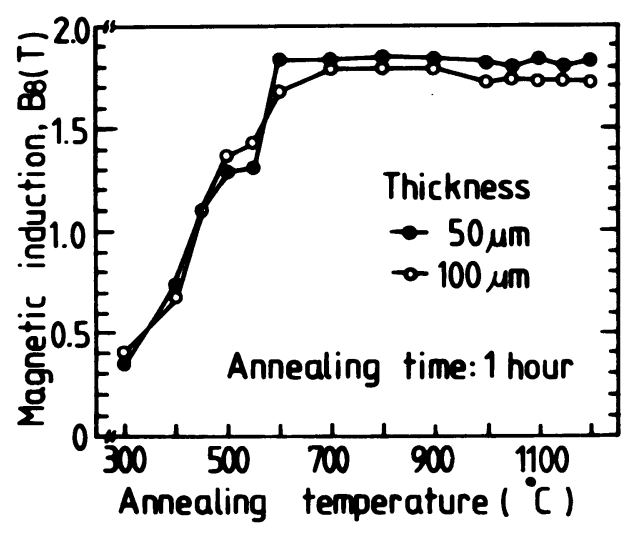

Fig. 7 The magnetic induction of thin foils annealed 1 hour a given temperatures 
Fig.7 shows the changes in the magnetic induction of the 0.100 and $0.050 \mathrm{~mm}$ thick sheets annealed a the given temperatures for 1 hour. As the annealing temperature is raised, the magnetic induction increases steadly and saturates to that of the initial regular grain oriented silicon steel sheet $\mathbf{a}$ and above annealing temperature of $600{ }^{\circ} \mathrm{C}$. This can be partly related to the development of the (110)[001] orientation in the recrystallized sheets, as were introduced in the previous figures.

\section{CONCLUSIONS}

The (110)[001] grains of regular grain oriented silicon steel appear to rotate into (111)[112] with increasing cold reduction ratio. This (111)[112] orientation returns back to the (110)[001] with recrystallization annealing. The stronger (111)[112] orientation developed by cold rolling seems to develop the stronger (110)[001] orientation with recrystallization annealing. The magnetic properties of the annealed sheets are found to improve with the increased (111)[112] orientations in the cold rolled sheet which was initially secondary recrystallized. When the cold rolled sheets of 0.100 and $0.050 \mathrm{~mm}$ thick were annealed to and above $600{ }^{\circ} \mathrm{C}$ for 1 hour, the magnetic induction at $800 \mathrm{~A} / \mathrm{m}$ was found to restore to those of the initial $0.30 \mathrm{~mm}$ thick regular grain oriented silicon steel sheets.

\section{ACKNOWLEDGEMENTS}

The financial support of the Ministry of Science and Technology of Korea is gratefully acknowledged. The authors would like to thank Prof. K. I. Arai of Tohoku University for his valuable advices and kind permission to use his rolling machine having a roll diameter of $50 \mathrm{~mm}$.

\section{REFERENCES}

1. M. F. Littmann; J. Appl. Phys., Vol. 38(1967), p.1104

2. U.Nishiike, K. Matsumura and Y. Ito; J. of the Magn. Soc. of Japan, Vol. 12, No. 1(1988), p.19

3. T. Yamaguchi and K. Takeda; IEEE Trans. Magn.,MAG-21, Jan. (1985), p.41

4. K. Takeda and T. Yamaguchi; IEEE Trans. Magn., MAG-23, No. 5, Sep. (1987), p.3233

5. K. I. Arai and K. Ishiyama; J. Appl. Phys., 64, No. 10(1988), p.5352

6. K. I. Arai, K. Ishiyama and H. Mogi; IEEE. Trans. Magn., Vol. 25, No. 5 Sep.(1989), p.3949

7. R. M.S. B. Horta, W. T. Roberts and D. V. Wilson; Trans. of the Metal Soc. of AIME, Vol. 245(1969), p.2525

8. T. Wada, K. Kuroki and J. Harase; J. of the Japan Inst. of Matals, Vol. 40, No. 11(1976), p.1158 